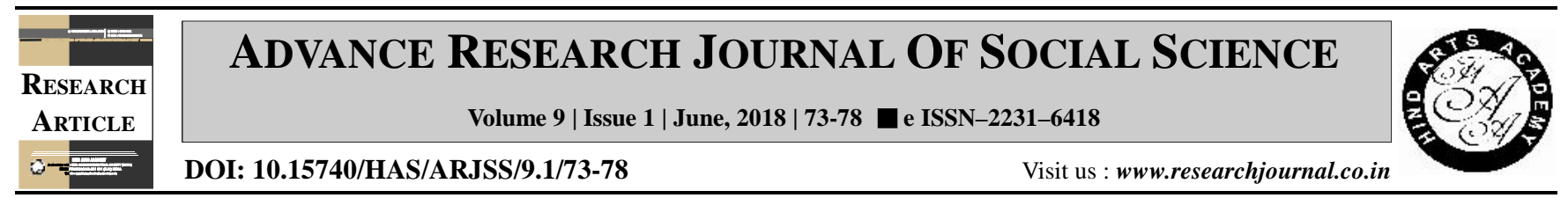

\title{
Impact of technology usage on social maturity of teenagers: Locale differentials
}

Deepali Dogra* and Seema Sharma

Department of Human Development and Family Studies, Punjab Agricultural University, Ludhiana (Punjab) India (Email: deepaliraj76@gmail.com; Seema30sept@pau.edu)

\section{ARTICLE INFO :}

$\begin{array}{lll}\text { Received } & : & 21.02 .2018 \\ \text { Revised } & : & 05.05 .2018 \\ \text { Accepted } & : & 20.05 .2018\end{array}$

\section{KEY WORDS :}

Social maturity, Technology usage

HOW TO CITE THIS ARTICLE :

Dogra, Deepali and Sharma, Seema (2018). Impact of technology usage on social maturity of teenagers: Locale differentials. Adv. Res. J. Soc. Sci., 9 (1) : 73-78, DOI: 10.15740/HAS/ARJSS/9.1/ 73-78.

Copyright@2018 : Hind Agri -

Horticultural Society

*Author for correspondence

\begin{abstract}
The present research study was aimed at to assess the impact of technology usage on social maturity of teenagers. The study was carried out in Ludhiana district on sample comprised of 200 rural and urban teenagers in age-group of 16 to 18 years studying in $11^{\text {th }}$ and $12^{\text {th }}$ grade in the selected Government Senior Secondary School of urban and rural areas. Further the sample was equally distributed over two sexes (Boys=100, Girls=100) from rural and urban areas. Social maturity scale by Rao (1986) and technology usage questionnaire was used to assess the social maturity and usage of technology of teenagers. Result revealed that very few teenagers had a high level of social maturity. And there was positive correlation between technology usage and social maturity among urban teenagers whereas, negative association between technology usage and social maturity was found among rural teenagers.
\end{abstract}

